\title{
Production of Xylose from Brewers Spent Grain by Dilute Hydrochloric Acid Hydrolysis.
}

\author{
Damascus Masawi ${ }^{1}$, Soloman Manyere ${ }^{2}$ and Fortunate Mugero \\ damascusmasawi@gmail.com and smanyere@gmail.com
}

Department of Bachelor of Technology in Chemical Technology in Affiliation with National University of Science and Technology (NUST), Harare Polytechnic, Box CY 407, Harare, Zimbabwe.

\begin{abstract}
The hemicellulosic fraction of brewer's spent grain (BSG) a waste from the brewing process obtained from National Breweries Harare, Zimbabwe was hydrolysed with dilute hydrochloric acid (HCI) of different concentration range from $1-5 \%$ in an auotoclave at 1.5 bar for $30 \mathrm{mins}$. The BSG hydrolysate impurities were removed by activated carbon using a platform shaker, filtered through a filter paper using a vacuum filter pump. The BSG hydrolysate was characterised by TLC, refractometer, FTIR and UV-VIS spectrophotometer at $540 \mathrm{~nm}$ using phenol sulphuric acid method. The results obtained showed positive identification of xylose. Optimum yield of $85 \%$ was obtained at $4 \%$ dilute HCI. The BSG dilute HCI acid hydrolysate can be an alternative source of xylose.
\end{abstract}

Key words: Xylose; brewers spent grain (BSG); acid hydrolysis; hemicellulose

\section{Introduction}

Brewers spent grains (BSG) the barley malt residue obtained after wort manufacture, is the main by-product of the brewery industry, representing $85 \%$ of total by- products generated[1]. BSG tend to be difficult to dispose off because of the large amounts produced after the brewing process as well as their high moisture content. If not disposed off on time, they give off odours in the brewery due to the development of spoilage organisms, hence affecting hygiene standards in the brewery. This also increases the biological oxygen demand (B.O.D) levels in the brewery. BSG has received little attention as a marketable commodity and is mainly used as animal feed[2]. BSG is a material that presents in its composition sugars polymerized into cellulose and hemicellulose mainly composed of hemicelluloses which can be converted by acid hydrolysis into xylose, a sugar that can be converted into xylitol or ethanol production [3].

Xylose is a rare sugar that exists in low amounts in nature. It acts as an excellent sweetener with some health benefits, especially in its ability to combat dental cavities, to treat illnesses such as diabetes, disorders in metabolism, parental and renal lesions and to prevent lung infection [4]. Xylose is also the raw material used in the manufacture of Xylitol. Xylitol is a natural five-carbon sugar alcohol that has attracted much attention recently because of its potential use as a natural food sweetener and an insulin-independent carbohydrate source for insulin-dependent diabetics, as well as its potential ability to reduce dental caries [5].

Hemicelluloses rich materials can be hydrolysed by various processes, among which dilute acid hydrolysis is one of the most efficient to selectively release hemicellulosic xylose, leaving a residue containing the cellulose and lignin fractions unaltered[6]. The major problem

ACRID 2017, June 20-21, Victoria Falls, Zimbabwe

Copyright (C) 2017

DOI 10.4108/eai.20-6-2017.2270207 
of acid hydrolysis is to conduct the process under adequate reaction conditions in order to obtain the maximum yield from the reaction.

The study deals with optimum parameters of dilute HCI acid hydrolysis of BSG hemicellulose to produce maximum amount of xylose. Reactions were performed in an autoclave at a constant temperature and reaction time and under different concentrations of hydrochloric acid, which were selected based on values used for the acid hydrolysis of other lignocellulosic materials [7],[8]. Xylose production was evaluated for each hydrolysate produced. The best hydrolysis condition to extract the hemicelluloses-derived xylose generating the highest yield was established by varying the HCI concentration.

\section{Experimental section}

\section{Brewer's spent grain}

The BSG used in this work was obtained from Harare Brewery, Zimbabwe. The BSG was first washed with deionized water until neutral $\mathrm{pH}$ was achieved, dried at $50^{\circ} \mathrm{C}$ to $10 \%$ moisture content and stored until required for processing.

\section{Chemical and reagents}

All chemical and reagents used were of analytical grade. Hydrochloric acid and sulphuric acid were obtained from Skylabs South Africa.

\section{Hydrolysis of BSG}

Hydrochloric acid of 1, 2, 3, 4 and 5\% concentrations were prepared and used for the hydrolysis reaction. $50 \mathrm{~g}$ of dried BSG were weighed into 5 Schott bottles, where $300 \mathrm{ml}$ of dilute hydrochloric acid of concentration range of $1 \%-5 \%$ were added to the Schott bottles. Reactions were carried out at $120^{\circ} \mathrm{C}(1.5$ bars $)$ in an autoclave for 30 minutes. After hydrolysis the resulting solid material was separated by filtration through a filter paper by a vacuum filter. Impurities in the hydrolysates were removed by means of activated carbon from charcoal using a platform shaker at 200rpm for $2 \mathrm{hs}$. The purified hydrolysates were filtered through a filter paper by a vacuum filter, allowed to crystallize and characterized for xylose by thin layer chromatography (TLC), refractometer, fourier transform infrared (FTIR) spectroscopic analysis and ultra violet visible (UV-VIS) spectrophotometer.

Table 1.Mass of BSG and volume of varying dil HCI used in the hydrolysis reaction.

\begin{tabular}{llllll}
\hline Sample & $\begin{array}{l}\text { Mass of } \\
(\mathrm{g})\end{array}$ & BSG & $\begin{array}{l}\text { Volume of HCI } \\
\text { used }(\mathrm{ml})\end{array}$ & $\begin{array}{l}\text { Concentration } \\
\text { of HCI }\end{array}$ & $\begin{array}{l}\text { Time taken for autoclaving } \\
(\mathrm{mins})\end{array}$ \\
1 & $50 \mathrm{~g}$ & $300 \mathrm{ml}$ & $1 \%$ & 30 \\
2 & $50 \mathrm{~g}$ & $300 \mathrm{ml}$ & $2 \%$ & 30 \\
3 & $50 \mathrm{~g}$ & $300 \mathrm{ml}$ & $3 \%$ & 30
\end{tabular}




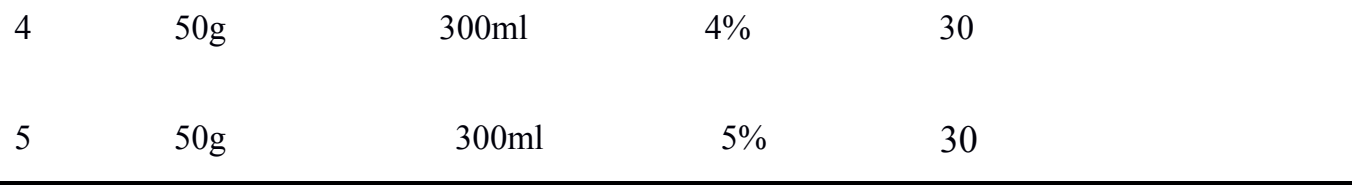

\section{Thin layer chromatography}

The mobile phase was prepared from acetone and deionised water at a ratio of $3: 1$. Silica plates were prepared and were clearly marked for sample identification. The samples and standard were then spotted onto the plates and left to run in the solvent. The plates were then visualized using a UV lamp and the retention factor (RF) was measured against the standard.

\section{Refractometry (TS meter)}

A digital hand held refractometer was used to determine the presence of a reducing sugar by measuring the Brix value of the hydrolysates.

\section{FTIR spectroscopic analysis}

The FTIR spectroscopic analysis was used in order to confirm that the hydrolysates were xylose. FTIR spectra of xylose crystals were collected by taking $32 \mathrm{scan}$ at $2 \mathrm{~cm}^{-1}$ resolution. The spectra were scanned from 4000 to $400 \mathrm{~cm}^{-1}$ and all samples were taken in potassium bromide $(\mathrm{KBr})$ and were compared to the standard xylose spectra [9]

\section{UV-VIS analysis of xylose}

\section{Determination of xylose concentration by phenol-sulphuric acid.}

The xylose was determined by the phenol sulphuric acid method using UV-VIS spectrophotometer at $540 \mathrm{~nm}$. The quantification of the hydrolysates samples was made from the calibration curve obtained using xylose standards. [10]

Table 2.Standards solutions for calibration curve.

Stock: $10 \mathrm{~g} / \mathrm{LD}(+)$ Xylose

\begin{tabular}{|c|c|c|c|c|c|c|}
\hline \multirow{2}{*}{$\begin{array}{l}\text { Desired } \\
\text { ppm }\end{array}$} & \multirow[t]{2}{*}{ Concentration } & \multirow{2}{*}{$\begin{array}{l}\text { Dilution } \\
\text { Needed }\end{array}$} & \multirow{2}{*}{$\begin{array}{l}\text { Volume } \\
\text { (ml) }\end{array}$} & Volume & \multirow{2}{*}{$\begin{array}{l}\text { Total } \\
(\mathrm{ml})\end{array}$} & \multirow[t]{2}{*}{ Volume } \\
\hline & & & & $\begin{array}{l}\mathrm{H}_{2} \mathrm{O} \\
\text { added }\end{array}$ & & \\
\hline 1. & 0 & none & 0 & 10.0 & 10.0 & \\
\hline 2. & 25 & $1: 40$ & 0.25 & 9.75 & 10.0 & \\
\hline 3. & 50 & $1: 20$ & 0.5 & 9.5 & 10.0 & \\
\hline 4. & 100 & $1: 10$ & 1.0 & 9.0 & 10.0 & \\
\hline 5. & 200 & $1: 5$ & 2.0 & 8.0 & 10.0 & \\
\hline
\end{tabular}




\section{Preparation of blank solution}

A blank solution was prepared by adding $1 \mathrm{ml}$ of $5 \%$ phenol to $1 \mathrm{ml}$ of deionised water, followed by $5 \mathrm{ml}$ of concentrated $\mathrm{H}_{2} \mathrm{SO}_{4}$.[10]

\section{Preparation of standard solution}

From a $100 \mathrm{ml}$ stock solution of xylose prepared in deionised water, aliquots were taken to obtain sugar concentrations of $60-90 \mathrm{mg} / \mathrm{ml} .1 \mathrm{ml}$ of $5 \%$ phenol solution was added to $1 \mathrm{ml}$ of sugar solution followed by $5 \mathrm{ml}$ of concentrated $\mathrm{H}_{2} \mathrm{SO}_{4}$. The absorbance was measured after 10 minutes at 540nm against blank. [10]

\section{Estimation of xylose in BSG hydrolysate}

$10 \mathrm{mg}$ of BSG hydrolysate xylose crystals were dissolved in $100 \mathrm{ml}$ of deionised water. To estimate the xylose content in BSG, $1 \mathrm{ml}$ of $5 \%$ phenol was added to the $1 \mathrm{ml}$ of BSG hydrolysate solution, followed by $5 \mathrm{ml}$ of concentrated $\mathrm{H}_{2} \mathrm{SO}_{4}$. The absorbance was measured after 10 minutes at $540 \mathrm{~nm}$ against blank and the concentration was calculated from the regression equation obtained from the calibration curve. The experiment was carried out in triplicate. [10]

Recovered sugar yield YS (g of substance that can be obtained from $100 \mathrm{~g}$ of BSG dry matter) and hydrolysis efficiency $\eta(\%)$ were calculated using Eqns (1) and (2) respectively, where C is the concentration of the component in the liquid phase $\left(\mathrm{g} \mathrm{dm}^{-3}\right), \mathrm{M}$ is the amount of BSG (dry matter) employed in the experiment $(\mathrm{g}), \mathrm{V}$ is the volume of liquid solution employed $\left(\mathrm{dm}^{3}\right)$ and Ymax is the maximum yield of recovered sugars that can be attained ( $\mathrm{g}$ per $100 \mathrm{~g}$ dry matter).

$$
\begin{aligned}
& \mathrm{YS}=(\mathrm{C} \times \mathrm{V} / \mathrm{M}) \times 100 \\
& \eta=(\mathrm{YS} / \mathrm{Ymax}) \times 100
\end{aligned}
$$

\section{RESULTS AND DISCUSSION}

\section{Thin layer chromatography}

Table 3.TLC Results

\begin{tabular}{lll}
\hline Sample & Distance moved by sample $(\mathrm{cm})$ & Retention value(Rf) \\
$1 \%$ & 6.1 & 0.85 \\
$2 \%$ & 6.3 & 0.87 \\
$3 \%$ & 6.3 & 0.87 \\
$4 \%$ & 6.1 & 0.87 \\
$5 \%$ & 6.1 & 0.86 \\
Standard & 6.1 & 0.86 \\
Solvent & 7.1 & \\
Front & & \\
\hline
\end{tabular}


From the results in table 3, the Rf values of the BSG hydrolysates were comparable to that of the standard xylose.

\section{Refractometer Analysis}

Table 4.Refractometer results

\begin{tabular}{lll}
\hline $\begin{array}{c}\mathrm{HCI} \\
\text { hydrolysis }\end{array}$ & used & in \\
$1 \%$ & sample & Brix \% \\
$2 \%$ & 7 \\
$3 \%$ & 11 \\
$4 \%$ & 25 \\
$5 \%$ & 28 \\
\hline
\end{tabular}

From the results in table 4 the presence of a reducing sugar was noted because of the notable brix levels in the hydrolysates. This confirms that hydrolysis did take place and a reducing sugar was produced.

FTIR spectra of BSG hydrolyses

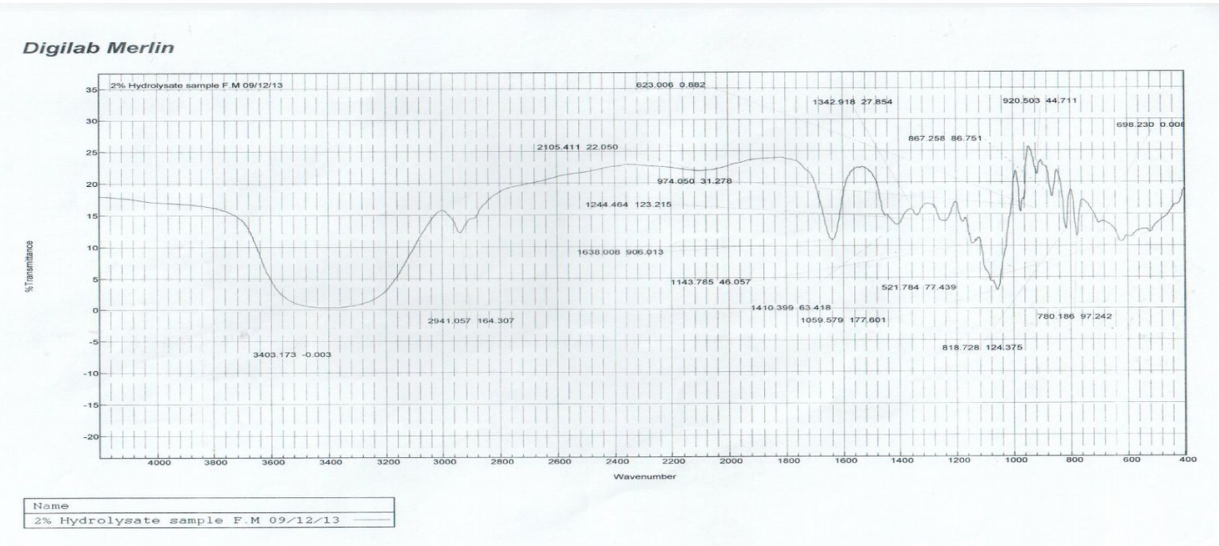

Fig. 1. FTIR spectra of BSG hydrolysate 
The FTIR spectra in fig. 1 identified the functional groups present. The band at $3300 \mathrm{~cm}^{-1}$ is assigned to the stretching of the $-\mathrm{OH}$ groups. The $\mathrm{C}-\mathrm{O}$ Stretching vibration gives signals at 2923 and $2850 \mathrm{~cm}^{-1}$. In the carbonyl stretching region, a strong signal at $1680 \mathrm{~cm}^{-1}$ is due to the absorbed water, since hemicelluloses usually have a strong affinity for water. The adsorption peaks in the 1200 to $800 \mathrm{~cm}^{-1}$ region originated from the $\mathrm{C}-\mathrm{O}$ stretching about the main polysaccharides. The peaks at 1350 and $1230 \mathrm{~cm}^{-1}$ represents $\mathrm{C}-\mathrm{H}$ bending and $\mathrm{O}-\mathrm{H}$ or $\mathrm{C}-\mathrm{O}$ bending vibration in hemicellulose. The presence of these functional groups in the hydrolysates that took place at different acid concentrations indicates that hydrolysis was successful and confirms that xylose was extracted from BSG.

\section{Quantification of Xylose Concentration in BSG Using Phenol-Sulphuric Acid UV-VIS method}

The phenol -sulphuric acid UV-VIS method was used to quantify the xylose and to identify the type of sugar present. A brown colour was produced, which indicates an aldehyde group and confirms that a pentose was produced.

\section{Calibration curve}

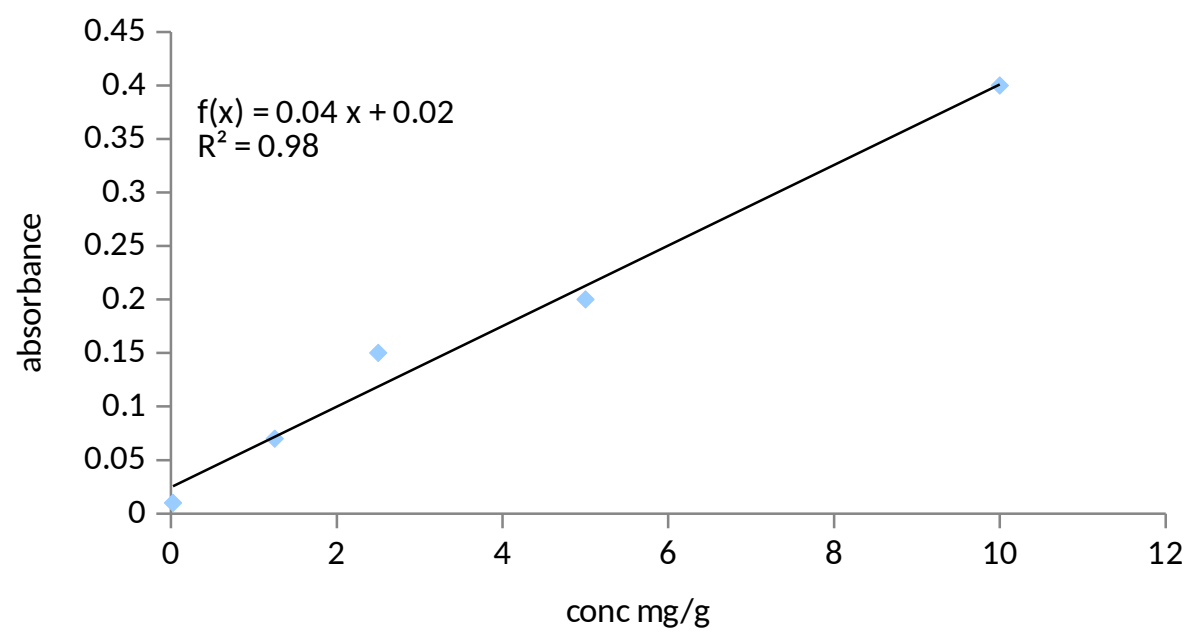

Fig. 3.Calibration curve for xylose standard

From fig. 3 calibration curve obtained from xylose standards using UV-VIS at 540nm, the concentrations of the xylose hydrolysates samples were determined and the results are shown in table 6. 


\section{Sugar concentration}

Table 6.Concentration of hydrolysate obtained from the calibration curve

\begin{tabular}{|c|c|c|c|c|c|c|}
\hline $\begin{array}{l}\% \\
\%\end{array}$ & used in & $\begin{array}{l}\text { Xylose } \\
(\mathrm{mg} / \mathrm{ml})\end{array}$ & concentration & $\begin{array}{l}\text { Xylose } \\
\text { yield }\end{array}$ & $\%$ & $\begin{array}{l}\text { Hydrolysis efficiency } \\
(\%)\end{array}$ \\
\hline 1 & & 0.054 & & 32.4 & & 32.4 \\
\hline 2 & & 0.069 & & 41.4 & & 41.4 \\
\hline 3 & & 0.118 & & 70.8 & & 70.8 \\
\hline 4 & & 0.146 & & 87.6 & & 87.6 \\
\hline 5 & & 0.101 & & 60,6 & & 60,6 \\
\hline
\end{tabular}

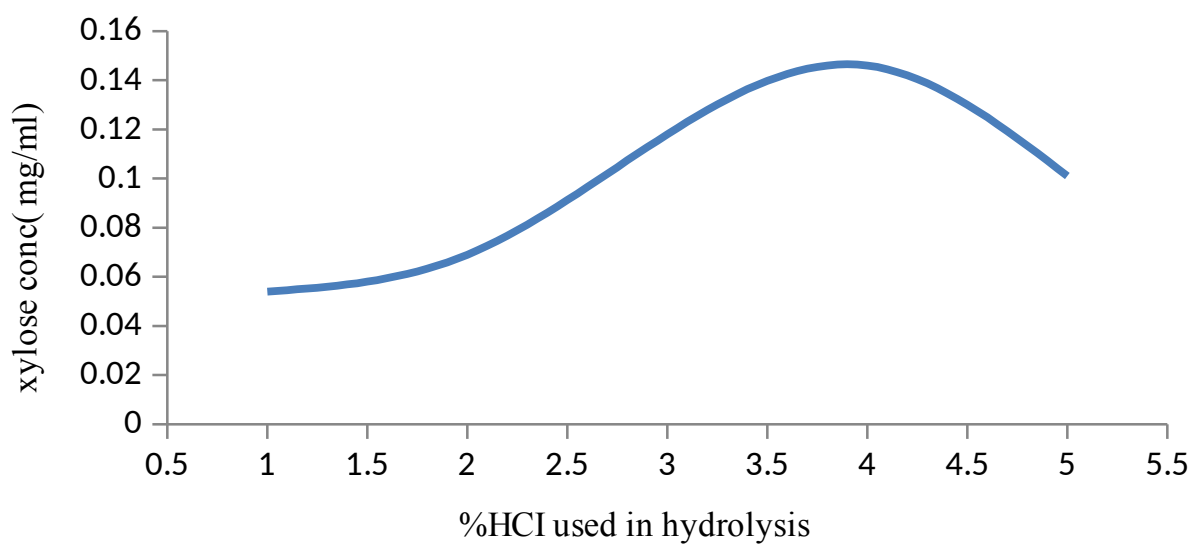

Fig. 4. Variation of xylose concentration with $\% \mathrm{HCI}$

Fig. 4 indicates that the yield increases as the acid concentration increases, up to a maximum xylose concentration of $0.146 \mathrm{mg} / \mathrm{ml}$ (yield of $87.6 \%$ ) at $4 \% \mathrm{HCI}$ acid concentration and then starts decreasing as concentration increases from $4 \%$. The higher the concentration of the acid, the greater the concentration of xylose produced. Further increase in the HCI concentration decelerated the rate of hydrolysis due to the decrease of the reactivity of cellulosic material in the course of hydrolysis at higher $\mathrm{pH}$. 


\section{Conclusion}

BSG is a biomass with great potential for xylose production by dilute HCI hydrolysis, because the xylose produced had a high yield and high hydrolysis efficiency. Employing BSG to produce xylose can be an alternative use for this agro-industrial by-product, with the advantage of producing a value-added by-product.

\section{References}

[1]. Ozturk S, " Ozboy " O, Cavidoglu I and K " oksel H, Effects of " brewer's spent grain on the quality and dietary fibre content of cookies. J Inst Brew. 108, 23--27 (2002)

[2]. Mussatto SI and Roberto IC, Optimal experimental condition for hemicellulosic hydrolyzate treatment with activated charcoal for xylitol production. Biotechnol Prog. 20,134--139 (2004)

[3] Nigam JN, Bioconversion of water-hyacinth (Eichhorniacrassipes) hemicellulose acid hydrolysate to motor fuel ethanol by xylose-fermenting yeast. J Biotechnol. 97,107--116 (2002)

[4] Mussatto SI and Roberto IC, Xylitol: a sweetner with benefits for human health. Braz J Pharm Sci. 38,401--413 (2002)

[5]. Palmqvist E and Hahn-Hagerdal B, Fermentation of lignocellu-losichydrolysates. II: Inhibitors and mechanisms of inhibition. Bioresource Technol. 74, 25--33 (2000)

[6]. McMillan JD, Pretreatment of lignocellulosic biomass. ACS Symp Ser. 566,292--324 (1994)

[7]. Kim T, Lee Y, Kim P, Kim CS and Oh D, Increased xylitol production rate during long term cell recycle fermentation of Candida tropicalis. Biotechnol Lett.26, 623--627 (2004).

[8]. Pessoa A, Jr, MancilhaM and Sato S, Acid hydrolysis of hemicellulose from sugarcane bagasse. Braz J Chem Eng. 14, 291--297 (1997).

[9]. Cardenas.G and Miranda. PTGA_FTIRofPdSn. Fine solid supported on Mgo. clohexane.J.Chil.Chem.Soc.49 N3, 267--271 (2004)

[10]. Albalasmeh A. A., Berhe A. A, Ghezzehei T. A. A new method for rapid determination of carbohydrate and total carbon concentrations using UV spectrophotometry, Carbohydr. Polym. 97, 253--261 (2013) 